\title{
Numerical Simulation of the Erosion Phenomenon at the Knee Tube at Different Angles Using DOE Method
}

\author{
Ayed Alshammari', Faramaz Djavanroodi², Esam Jassim $^{3}$ \\ Prince Mohammad Bin Fahd University \\ Khobar, Saudi Arabia \\ 201500404@pmu.edu.sa; fdjavanroodi@pmu.edu.sa \\ ${ }^{2}$ Prince Mohammad Bin Fahd University \\ Khobar, Saudi Arabia \\ ejassim@pmu.edu.sa
}

\begin{abstract}
This numerical study is considered to investigate the erosion in the pipeline systems affected by different parameters such as elbow angle and type, mass flow rate, pipe radius, and wall materials using Computational Fluid Dynamics (CFD). the gravity effect has been considered along the Y-direction. The Standard k- $\varepsilon$ model has been selected for turbulence, and standard wall functions have been used for near-wall treatment. Discrete phase modelling (DPM) is selected to model the secondary phase (sand particles). The continuous phase is crude oil, and the discrete phase is sand. The particle characteristics were selected based on the region of Saudi Arabia. Validations are conducted based on the maximum erosion rate at different inlet velocities and particle sizes. Four different elbow angles included 90, 60, 45, and 30 degrees and two types of elbow included sharp and smooth elbow was used to study the behaviour of the erosion rate. The roughness height is selected to introduce the wall material; considering that, each material has a specific roughness height. Therefore, the recognition of every material in this study is done by roughness height. Three parameters of the mass flow rate, tube radius, and roughness height are considered as input parameters to perform the DOE. The DOE study showed that the pipe radius has the most effect on the erosion rate. The reason rate in the Generic models for different angles with curvature $(5 \mathrm{D}) 90^{\circ}, 60^{\circ}, 45^{\circ}, 30^{\circ}$ are $5.6 \times 10^{-10}, 2.7 \times 10^{-10}, 1.5 \times 10^{-9}, 3.96 \times 10^{-10}$ respectively.
\end{abstract}

Keywords: Erosion - CFD - Elbow - DOE - DPM

\section{Introduction}

Piping is an operation in the industry that results in the transfer of various fluids from one point to another. Usually, in the industry, the fluid flow is not pure and always carries some particles. When particles, such as sand, are dissolved in the fluid in a pipe, there is a possibility of erosion and tear on the pipe wall. However, when there is a sudden change in the tube's direction, such as the knees, this undesired phenomenon could be augmented. The presence of impurities and particles such as sand in the fluid flow in a pipe has always been associated with many problems and difficulties. The movement of these particles and the background fluid flow cause destructive phenomena such as wear and corrosion inside the pipes. This damage is more noticeable on the surface of the pipe's inner body particularly, in regions that have change in the direction of flow. Elbow joints in pipes are one of the main areas affected by wear inside pipes. The target of researches were to investigate the factors, which affect the erosion rate. M. Zamani et al. [1] focused on various key parameters, including gas flow velocity, solid particle diameter, and particle mass flow rate. Their numerical work showed that the particles' rotational motion strongly influences the wear rate in the elbows. In some numerical studies, researchers mainly focus on the effect of the geometric parameters of bends or elbows in pipelines [2,3].

As researchers moved toward simulating the phenomenon of erosion using the DPM model in Fluent software, they were challenged how to quantify the erosion rate based on the mathematical formulation. Oka et al. [4] focused on the effect of pipe material on the amount of wear rate produced. S. Lain et al. [5] also combined the Eulerian-Lagrange perspective with the erosion model proposed by Oka et al. They tried to study the effects of wall roughness, particle impact and mass load applied on the penetration ratio as a measure of the intensity of wear at one elbow of transmission lines. Finnie et al. [6] simulated the mechanism of material destruction of wear-induced surfaces in the range of transition from malleable to brittle. 
They focused on the behaviour of abrasive particles without considering corrosion. Maclaury et al. [7] proposed a model for determining the rate of wear in slurry or dense gas flows.

\section{Mathematical Model}

Four different models are used to calculate the erosion damage caused by solid particle impact. These models use the following parameters to calculate the erosion:

- $\quad$ Particle impact velocity,

- $\quad$ Particle impact angle,

- Mechanical properties of materials.

Each model proposes a correlative equation between impact parameters and erosion damage caused by solid particle impact.

1. The Finnie Erosion Model state that the erosion of ductile metals varies with impact angle and velocity according to the below equation [12]:

$$
E R=m^{k v^{n}} f(\propto)
$$

Where

$\mathrm{m}$ : Mass flow rate of the particles

$\mathrm{k}=$ Empirical Constant,

$\mathrm{n}=$ Velocity index

$\mathrm{f}(\alpha)=$ Impact Angle Function

2. Oka Erosion Model proposes an equation for estimating erosion damage for any impact conditions and materials. The size, shape, and properties of particles, impact velocity, and angle are the main parameters that affect erosion mechanisms and damage to materials. The material parameters are mechanical properties such as material hardness. The erosion rate (ER) is determined as [12]:

$$
\mathrm{ER}=E_{90}\left(\frac{V}{V_{\text {ref }}}\right)^{k_{2}}\left(\frac{D}{D_{\text {ref }}}\right)^{k_{3}} f(\propto) m
$$

Where

$\mathrm{E} 90=$ reference erosion ratio at $90^{\circ}$ impact angle

$\mathrm{V}=$ particle impact velocity

Vref $=$ reference velocity

$\mathrm{d}$ and dref $=$ particle diameter and particle reference diameter, respectively

$\mathrm{k} 2$ and $\mathrm{k} 3=$ velocity and diameter exponents, respectively

$f(\propto)=$ impact angle function

3. McLaury proposed a model for predicting the erosion rate of sand particles in water. The McLaury erosion rate (ER) is determined by [12]:

$$
E R=A V^{n} f(\propto) m
$$

Where

A = Empirical constant

$\mathrm{V}$ : Particle impact velocity

$\mathrm{n}$ : Velocity exponent

$f(\alpha)=$ Impact Angle Function 
4. The erosion rate (Generic model) is defined as [12]:

$$
E R=\sum_{P=1}^{N \text { trajct }} \frac{\dot{m}_{p} C\left(d_{p}\right) f(\propto) v_{p}^{n}}{A_{\text {face }}}
$$

Where

$\dot{m}_{p}$ : Mass flow rate of the particles

$\mathrm{f}(\alpha)$ : Impact angle function

$v_{p}$ : Particle impact velocity

$\mathrm{n}$ : Velocity exponent

$C\left(d_{p}\right)$ : Particle diameter function

\section{Numerical Model}

The Erosion in elbows due to sand particles is simulated by ANSYS Fluent software. The results are compared with experimental and numerical results [7]. The pipe material is Stainless Steel 316. The recognition of every material in the software is done by three different parameters of hardness, density, and roughness height. four erosion rate models (Generic, Finnie, McLaury and Oka models) of ANSYS Fluent are used to validate the present results. To study the effect of geometrical parameters on erosion, different angles of elbow are modelled. Design modeler software is used to model the desired geometries. Table 1 shows the simulated geometries in this study.

Table 1 Simulating Geometries

\begin{tabular}{c|cccc}
\hline $\begin{array}{c}\text { Elbow angle } \\
\text { (degree) }\end{array}$ & $\begin{array}{c}\text { Elbow curvature } \\
\text { diameter }\end{array}$ & $\begin{array}{c}\text { Downstream } \\
\text { pipe length }\end{array}$ & $\begin{array}{c}\text { Upstream } \\
\text { pipe length }\end{array}$ & $\begin{array}{c}\text { Internal diameter } \\
\text { pipe (D) }\end{array}$ \\
\hline 30 & $5 \mathrm{D}$ & $1.8 \mathrm{~m}$ & $3.5 \mathrm{~m}$ & $0.15 \mathrm{~m}$ \\
\hline 45 & $5 \mathrm{D}$ & $1.8 \mathrm{~m}$ & $3.5 \mathrm{~m}$ & $0.15 \mathrm{~m}$ \\
\hline 60 & $5 \mathrm{D}$ & $1.8 \mathrm{~m}$ & $3.5 \mathrm{~m}$ & $0.15 \mathrm{~m}$ \\
\hline 90 & $1.5 \mathrm{D}$ & $1.8 \mathrm{~m}$ & $3.5 \mathrm{~m}$ & $0.15 \mathrm{~m}$ \\
\hline
\end{tabular}

\subsection{Validation}

To validate the present model, at first the particles diameters are modelled by constant size and finally the actual distribution of particle size is simulated by implementing Rosin-Rammler's expression. Table 2 shows the boundary conditions of the simulations which were used in the previous study and which we used in the present work. Different values were examined to achieve good agreement with the reference paper's experimental and numerical results. The velocity-inlet and pressure-outlet boundary conditions were used to specify the flow at inlet and outlet boundaries, respectively.

Table 2 Boundary Conditions

\begin{tabular}{ccccc} 
Case & $\begin{array}{c}\text { Inlet: Velocity- } \\
\text { Inlet }(\mathrm{m} / \mathrm{s})\end{array}$ & $\begin{array}{c}\text { Particle Size } \\
(\mu \mathrm{m})\end{array}$ & $\begin{array}{c}\text { Sand Flow } \\
\text { Rate }(\mathrm{kg} / \mathrm{s})\end{array}$ & $\begin{array}{c}\text { Outlet: } \\
\text { Pressure-Outlet }(\mathrm{Pa})\end{array}$ \\
\hline 1 & 11 & 150 & 0.00294 & 0
\end{tabular}




\begin{tabular}{rrrrr}
2 & 11 & 300 & 0.00333 & 0 \\
3 & 15 & 150 & 0.00274 & 0 \\
4 & 15 & 300 & 0.00119 & 0 \\
5 & 15 & $\operatorname{PSD}(177)^{*}$ & 0.00274 & 0 \\
6 & 23 & $\operatorname{PSD}(177)^{*}$ & 0.00297 & 0 \\
\hline
\end{tabular}

*Rosin-Rammler expression

After we set the boundary conditions, we investigate different velocity and sand particles size to match the results in reference paper's experimental and numerical results. Table 3 shows the results of reference paper's experimental and numerical results.

Table 3 Previous Experimental and Numerical Simulation For $90^{\circ}$ Elbow

\begin{tabular}{c|c|c|ccc|} 
Case & $\begin{array}{c}\text { Gas } \\
\text { Velocity } \\
(\mathrm{m} / \mathrm{s})\end{array}$ & $\begin{array}{c}\text { Sand Size } \\
(\mu \mathrm{m})\end{array}$ & Experimental & Numerical & $\begin{array}{c}\text { Percent } \\
\text { Bias \% }\end{array}$ \\
\hline 1 & 11 & 150 & 6.5 & 7.07 & 8.77 \\
2 & 11 & 300 & 16.9 & 20.65 & 22.19 \\
3 & 15 & 150 & 13.2 & 14.49 & 9.77 \\
4 & 15 & 300 & 14.7 & 17.05 & 15.99 \\
5 & 15 & $\operatorname{PSD}(177)$ & 13.2 & 12.63 & -4.32 \\
6 & 23 & $\operatorname{PSD}(177)$ & 36.2 & 37.78 & 4.36 \\
\hline
\end{tabular}

There results of present work in four different erosion model based on ansys software are presented in table 4 . Also the difference between the present work and reference paper's experimental work at investigated and show the percentage of error between the simulation and the experimental work to find the best model give us the least percentage of error. According to table 4 the the best two models give least percentage of error and more results close to the experimental work are the oka model and generic model. Also we noted when we use the Rosin-Rammler's sand particles distribution the simulation results become more accurate and close to the experimental work so the Rosin-Rammler's distribution enhance and improve the simulation results.

\begin{tabular}{c|c|c|cccccccc}
\multicolumn{1}{c}{ Table 4 show the results of the present work } \\
Case & $\begin{array}{c}\text { Gas } \\
\text { Velocity } \\
(\mathrm{m} / \mathrm{s})\end{array}$ & $\begin{array}{c}\text { Sand Size } \\
(\mu \mathrm{m})\end{array}$ & $\begin{array}{c}\text { Generic } \\
\text { Model }\end{array}$ & $\begin{array}{c}\text { Percent } \\
\text { Bias \% }\end{array}$ & $\begin{array}{c}\text { Oka } \\
\text { Model }\end{array}$ & $\begin{array}{c}\text { Percent } \\
\text { Bias \% }\end{array}$ & $\begin{array}{c}\text { Finnie } \\
\text { Model }\end{array}$ & $\begin{array}{c}\text { Percent } \\
\text { Bias \% }\end{array}$ & $\begin{array}{c}\text { McLaury } \\
\text { Model* }\end{array}$ & $\begin{array}{c}\text { Percent } \\
\text { Bias \% }\end{array}$ \\
\hline 1 & 11 & 150 & 7.17 & 9.34 & 6.68 & 2.69 & 9.57 & 32.07 & 11.78 & 44.82 \\
2 & 11 & 300 & 13.23 & 27.73 & 11.38 & 48.5 & 15.02 & 12.5 & 17.31 & 2.36 \\
3 & 15 & 150 & 16.33 & 19.16 & 14.05 & 6.04 & 18.75 & 29.6 & 18.02 & 26.74 \\
4 & 15 & 300 & 13.28 & 9.66 & 12.39 & 18.64 & 13.42 & 9.53 & 12.86 & 12.52 \\
5 & 15 & PSD(177) & 12.79 & 3.11 & 12.78 & 3.18 & 1.55 & 88.25 & 15.27 & 13.55 \\
6 & 23 & PSD(177) & 37.45 & 3.33 & 37.43 & 3.28 & 41.09 & 11.9 & 3.28 & 90.94 \\
\hline
\end{tabular}

\subsection{CFD Modelling}


The results of considered cases are represented and analysed. The effect of different angles and radius of elbows is investigated. Steady and Pressure-Based solver simulates the tube, also the gravity effect has been considered along the Ydirection. The Standard k- $\varepsilon$ model has been chosen as the turbulence model, and standard wall functions have been used for near-wall treatment. The continuous phase is crude oil with a density of $870 \mathrm{~kg} / \mathrm{m} 3$ and viscosity of $0.00072 \mathrm{~kg} / \mathrm{m}-\mathrm{s}$, and the discrete phase is sand with a density of $6650 \mathrm{~kg} / \mathrm{m} 3$. Mean, Max and Min diameters of sand particles are $2.4 \mathrm{~mm}, 3 \mathrm{~mm}$, and $1.5 \mathrm{~mm}$, respectively. The particle characteristics (like density and diameter) were selected based on the region of Saudi Arabia. [9]. For all cases, crude oil enters the pipe at a speed of $10 \mathrm{~m} / \mathrm{s}$, and sand is injected from the inlet. the non-slip condition has been applied to the wall. Table 5 shows the results of the erosion rate of different elbow's angles while we keep the curvature constant which is 5D. In all angels the Oka modes shows give grater erasion rate than Generic model.

Table 5 Maximum erosion rate for different elbow angles with two erosion rate models ( Oka and Generic)

\begin{tabular}{ccc}
$\begin{array}{c}\text { Angle } \\
(\text { degree })\end{array}$ & $\begin{array}{c}\text { Generic } \\
\left(\mathrm{kg} / \mathrm{m}^{2} \mathrm{~s}\right)\end{array}$ & $\begin{array}{c}\text { Oka } \\
\left(\mathrm{kg} / \mathrm{m}^{2} \mathrm{~s}\right)\end{array}$ \\
\hline 90 & $5.6 \times 10^{-10}$ & $9.2 \times 10^{-8}$ \\
\hline 60 & $2.7 \times 10^{-10}$ & $5.2 \times 10^{-8}$ \\
\hline 45 & $1.5 \times 10^{-9}$ & $1.94 \times 10^{-7}$ \\
\hline 30 & $3.96 \times 10^{-10}$ & $5.44 \times 10^{-8}$ \\
\hline
\end{tabular}

\section{Design of Experiments (DOE)}

Design of Experiments (DOE) is a set of measures that are performed using process modelling and related variables and lead to increased production efficiency. A set of different parameters that affect the outcome of a particular process is analysed to obtain the best possible values for the production of an optimal product. Therefore, the purpose of DOE is, firstly, which input factors or parameters will have a significant impact on the output result or product of the process, and secondly, how much of these input factors or parameters should be used to achieve the desired output result or product.

Three parameters of input mass flow rate [10], tube radius [11], and roughness height [13] are considered input parameters to perform the DOE. The DOE was performed by the Central Composite Design (CCD) method. Also, the CCD method uses the Auto Defined type. The interval of change of the simulated input parameters is shown in table 6.

Table 6 Range of Input Parameters

\begin{tabular}{|l|l|l|}
\hline Input parameter & Max value & Min value \\
\hline Tube radius & $40 \mathrm{in}$ & $4.5 \mathrm{in}$ \\
\hline Mass flow inlet & $200 \mathrm{~kg} / \mathrm{s}$ & $100 \mathrm{~kg} / \mathrm{s}$ \\
\hline Roughness height & $5 \mathrm{~mm}$ & $0.0015 \mathrm{~mm}$ \\
\hline
\end{tabular}

Figure 1 shows the effect of mass flow rate and roughness height on the erosion rate (Generic model) at 4.5 in tube radius. As it is obvious, the roughness height has more effect on the erosion rate compare to the mass flow rate. At high roughness heights, the mass flow rate has more effect on the erosion rate. By increasing the mass flow rate, the erosion rate decreases, since a higher mass flow rate provides more impact kinetic to abrasive particles and leads to a lower erosion rate [14]. According to figure 1 if the roughness height decreases this will leads to a lower erosion rate. Figure 2 shows the erosion rate (Oka model) changes as a function of mass flow rate and pipe radius at $0.0011512 \mathrm{~mm}$ roughness height. The mass flow rate parameter has a small effect on the erosion rate except for large tube radiuses. 


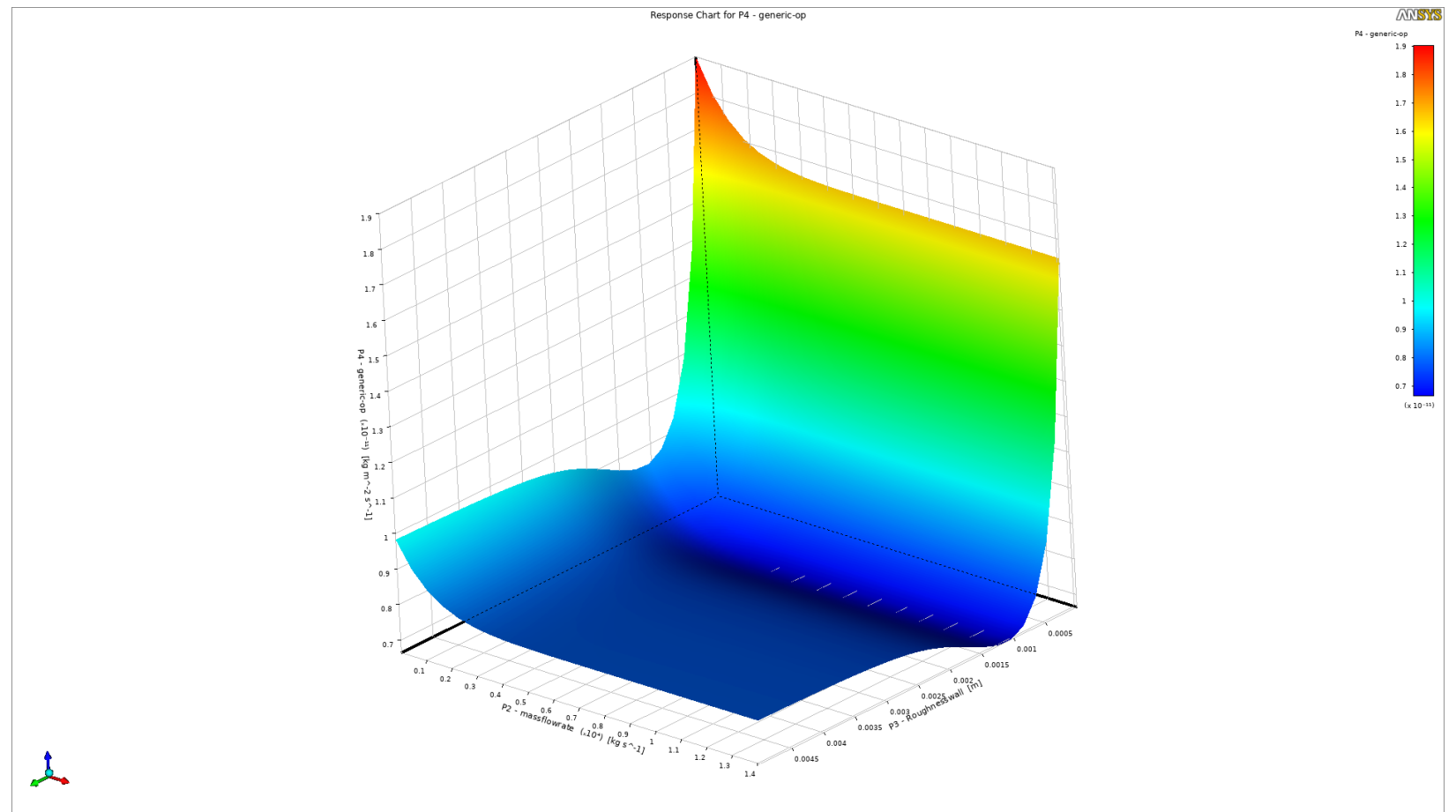

Fig. 1: Response surface of the Generic model in terms of two parameters of mass flow inlet and roughness height

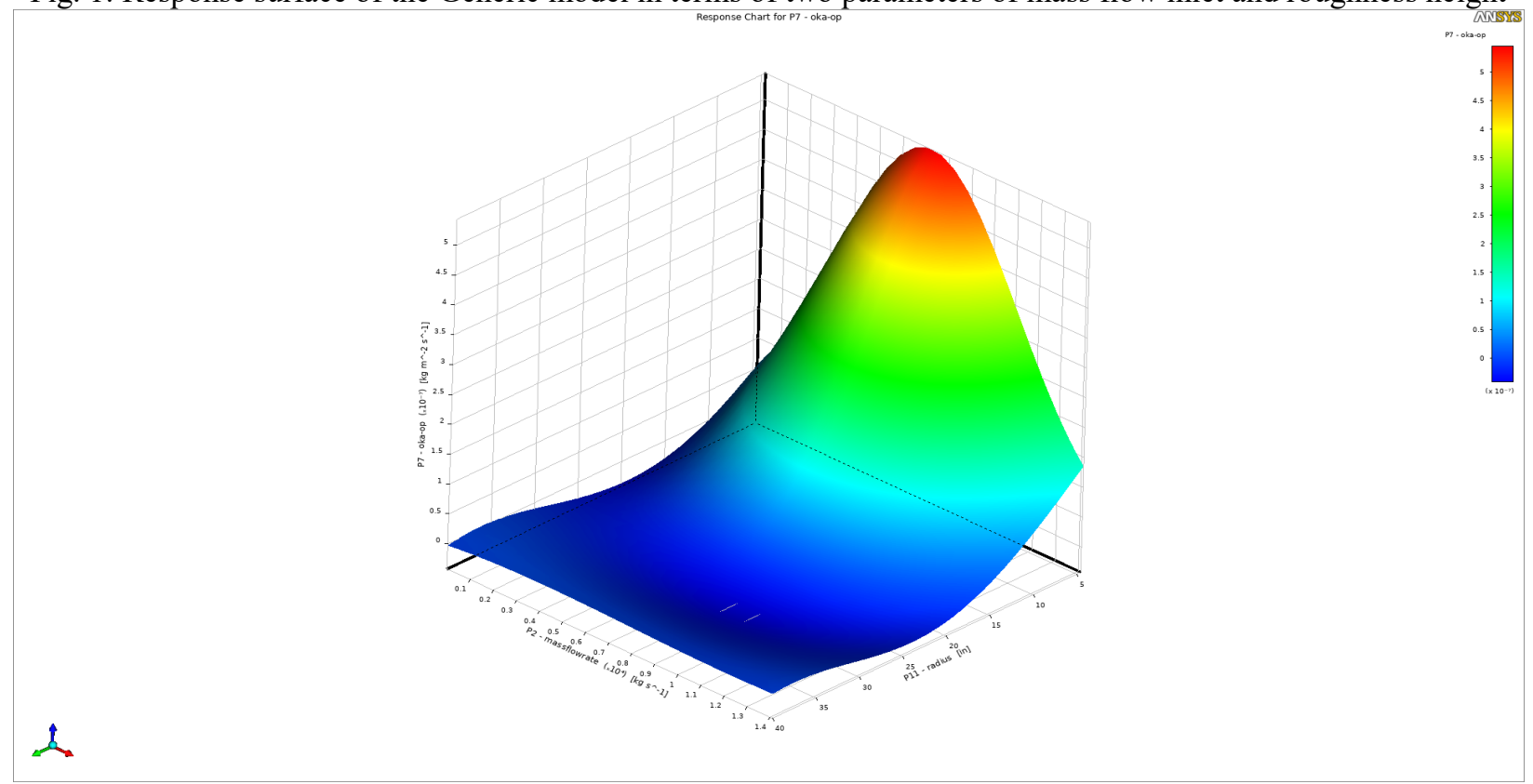

Fig 2: Response surface of Oka model in terms of two parameters of mass flow inlet and tube radius 


\section{Conclusion}

In this study, the effect of different erosion models and types of the elbow on erosion rate was investigated. Three parameters, the mass flow rate, the pipe radius, and the roughness height, were selected to do the DOE study. Lots of reliable results can be concluded from these current CFD simulations. First, it can be noticed that by increasing the fillet curve radius of the pipe knee, the erosion rate decreases. Another important issue is that the effect of three different input parameters of mass flow rate, pipe diameter, and pipe wall roughness height, on the erosion rate is studied using the DOE method. The pipe radius has the most impact on the erosion rate. Also, four different erosion rate equations have been investigated. Oka and Generic models present the best results in terms of erosion rate study.

\section{References}

[1] Mohammad Zamani, Sadegh Seddighi, Hamid Reza Nazif, Erosion of natural gas elbows due to rotating particles in turbulent gas-solid flow, Journal of Natural Gas Science and Engineering, 2017.

[2] Wee Siaw Khur, Yap Yung Jian, CFD study of sand erosion in pipeline, Journal of Petroleum Science and Engineering, 2018.

[3] V. Kannojiya, S. Kumar, Assement of Optimum Slurry Pipe Design for Minimum Erosion, Mechanical and Industrial Engineering Department, Indian Institute of Technology.

[4] M.A. Habib, H.M.Badr, R.Ben-Mansour, M.E.Kabir, Erosion rate correlations of a pipe protruded in an abrupt pipe contraction, International Journal of Impact Engineering 34 (2007) 1350-1369.

[5] Iain Finnie, Some reflections on the past and future of Erosion, Wear 186-187 (1995) 1-10.

[6] B.S. McLaury, Predicting Solid Particle Erosion Resulting From Turbulent Fluctuation in oil Field Geometries (Ph.D. dissertation), Department of Mechanical Engineering, The University of Tulsa, Tulsa, USA, 1996.

[7] Y.I. Oka, K. Okamura, T. Yoshida, Practical estimation of erosion damage caused by solid particle impact Part 1: Effects of impact parameters on a predictive equation, Wear 259 (2005) 95-101.

[8] Abolkhair, Yahya Mohammed Sheikh, The Statistical Analysis of the Sand Grain Size Distribution of A.I.- Ubaylah Barchan Dunes, Northwestern Ar-Rub-Alkhali Desert, Saudi Arabia

[9] American Petroleum Institute, API 5L: Specification for Line Pipe, 49 CFR 192.113

[10] F. Madani Sania , S. Huizingab , K.A. Esaklulc, S. Nesic, Review of the API RP 14E erosional velocity equation: Origin, applications, misuses, limitations and alternatives

[11] Pathegama Gamage Ranjith, Yong Liu, Jianping Wei and Xiaotian Liu. Effect of abrasive mass flow on the abrasive acceleration and erosion rates of abrasive gas jets, (C) Springer-Verlag GmbH Austria, part of Springer Nature 2019

[12] ANSYS Fluent, 12.0/12.1 Documentation, Users Guide Manual, Ansys Inc., 2009 Available: https://www.ansys.com//media/ansys/en-gb/presentations/2018+scottish+innovation+conference+presentations/2018ansys-innovations-erosionmodeling-sabrina-hafid.pdf?la=engb\&hash=3A3666DAA3FA78FF471EC8969E8756CB698AECEC

[13] Farshad, Fred F., and Herman H. Rieke. "Surface roughness design values for modern pipes." SPE Drilling \& Completion 21.03 (2006): 212-215. 